\title{
Preparation and Properties of Biosorbents on the Base of Fruit Seed Shell
}

\author{
Kartel Mykola ${ }^{1,2, *}$, Galysh Vita ${ }^{2,3}$, Wang Bo ${ }^{1}$, Mukalo Yevgen ${ }^{3}$, Kozakevych Roman ${ }^{2}$, \\ Nikolaichuk Alina ${ }^{2}$ \\ ${ }^{1}$ Technology and Business Department, Ningbo University of Technology, Ningbo, China \\ ${ }^{2}$ Department of Carbon Nanomaterials, O. Chuiko Institute of Surface Chemistry of NAS of Ukraine, Kyiv, Ukraine \\ ${ }^{3}$ Chemistry and Technology Faculty, I. Sikorsky National Technical University of Ukraine "Kyiv Polytechnic Institute", Kyiv, Ukraine
}

\section{Email address:}

nikar@kartel.kiev.ua (K. Mykola),v.galysh@gmail.com (G. Vita)

${ }^{*}$ Corresponding author

\section{To cite this article:}

Kartel Mykola, Galysh Vita, Wang Bo, Mukalo Yevgen, Kozakevych Roman, Nikolaichuk Alina. Preparation and Properties of Biosorbents on the Base of Fruit Seed Shell. International Journal of Materials Science and Applications. Vol. 8, No. 6, 2019, pp. $114-119$.

doi: $10.11648 /$ j.ijmsa.20190806.14

Received: August 19, 2019; Accepted: November 20, 2019; Published: December 3, 2019

\begin{abstract}
The process of obtaining of new biosorbents from apricot seed shells by oxidative-organosolvent processing in "acetic acid - hydrogen peroxide" medium has been studied. The structural and sorption properties of the materials obtained using physical and chemical methods were investigated. The effect of the reactants ratio in solution, as well as the duration of the modification process on the yield, content of cellulose, lignin, and mineral components and on sorption properties of the products was studied. The dependence between the mineral content and the adsorption pore volume was shown. The positive effect of hydrogen peroxide application in the process of modifying of plant waste on cellulose content was estimated. Increasing the duration of modification increases the contribution of oxidative transformation of lignin into soluble products and decreases the yield of the lignocelluloses' materials. The regularities of sorption of marker of low molecular weight toxins and non-steroidal anti-inflammatory drugs on obtained products were investigated. It has been found that the highest sorption capacity of obtained lignocelluloses' sorbents towards Methylene Blue and Sodium Diclofenac corresponds to the samples with polysaccharide content $60 \%$. It has been also found that the sorption equilibrium occurs within 120 min of contact. The obtained results demonstrate the feasibility of application of such lignocelluloses' carriers in the production of prolonged action drugs.
\end{abstract}

Keywords: Lignocelluloses, Oxidative-Organosolvent Processing, Removal Efficiency

\section{Introduction}

Vegetable raw materials are biopolymer recovery complexes consisting in mainly of cellulose, lignin and hemicelluloses. Lignocelluloses complex due to the presence different functional groups (methoxyl, hydroxyl, carbonyl, etc.) characterized by a number of valuable properties, allowing the use of vegetable raw materials in various industries. However, special scientific and practical interest today is an opportunity use of restorative plant raw materials for medical supplies purpose [1]. It is known that cellulose and its derivatives are used in various industries medicine, because both the polymers themselves and their breakdown products are non-toxic and harmless. It is also possible to obtain a wide range of cellulose derivatives given composition and properties [2].

Microcrystalline cellulose, oxidized cellulose, phosphates and cellulose acetates, as also other derivatives have become widespread use in pharmaceutical and medical practice [3-6]. Lignin, which is a by-product the product of chemical wood processing, too used in medicine as an enterosorbent, spectrum of adsorption activity which includes toxins of exoand endogenous nature, allergens, xenobiotics, heavy metals, radionuclides [7]. 
Today one of the promising directions development of "green chemistry" is the development of new ones multifunctional materials based on vegetable waste using low-energy and energy-efficient ways processing. This approach allows you to develop effective directions of plant utilization waste; for example, by chemical processing (modification) it is possible to get efficient, cheap and affordable environmental and medical biosorbents appointment. Biosorbents are absorbing materials based on vegetable raw materials (lignocelluloses complex) or based on its individual components (cellulose or lignin).

As affordable and cheap sources of these materials use different wastes vegetable origin: sawdust [8], bark [9], agricultural waste [10].

Multi-tonnage food industry waste can also be considered as a promising source of raw materials to obtain cheap kind of multifunctional sorbents $[11,12]$.

The properties of any sorbents are considerable extent is determined by the conditions of receipt, change which can affect the structure and chemical composition of materials. The source plant materials are characterized by weak sorption properties due to low fibrillation structure, low parity and availability in their stock is very small in number of free functional groups. To enhance the absorption of sorbents is different ways of processing the raw material mechanical, physical, chemical, but most often their combination.

Structural sorption characteristics absorbent materials based on vegetable polymers are highly content dependent from polysaccharide and aromatic component, the ratio of which determines the ability sorbents to swell, complexation and cation exchange. Using the method organosolvent modification of vegetable raw materials in the environment "acetic acid - hydrogen peroxide" and regulation the ratio of reagents allows obtaining lignocelluloses materials with predominant content of one or the other component, depending from the destination of the final product.

The purpose of the work is to receive and research properties of medical sorption materials appointment by modification shells of apricot stones in the medium "acetic acid - hydrogen peroxide".

\section{Materials and Methods}

For the preparation of lignocelluloses sorbents as a raw material is used shell of apricot stones. The source material is pre-crushed to $0.12 \mathrm{~mm}$ and stored in desiccators for maintenance constant humidity and chemical composition: content cellulose $-28.1 \%$, lignin $-48.3 \%$, ash $-0.8 \%$, of resins, fats and waxes $-7.6 \%$; substances that extracted with water $-7.1 \%$, alkali $-15.0 \%$ from the mass of absolutely dry raw materials. The component composition of the feedstock was determined in accordance with standard methodologies [13].

Organic salt modification - the method was carried out under different conditions: ratio of reagents $\mathrm{CH}_{3} \mathrm{COOH}(99.8$ wt.\%): $\mathrm{H}_{2} \mathrm{O}_{2}$ (35 wt.\%) = (90-70): (10-30) vol.\%, duration
30-150 min. Hydromodule and process temperature remained stable and were respectively $5: 1$ and $90^{\circ} \mathrm{C}$.

The specified value of the hydraulic module provides complete wetting of the original natural material by modifying solution. Respond-relative to the literature data $[14,15]$, a temperature of $90^{\circ} \mathrm{C}$ ensures receipt semi-finished products with maximum content polysaccharide component and is optimal for redox method of processing vegetable raw materials. For preparation of the original modifying solutions is used acetic acid and hydrogen peroxide of grade "chemical pure".

Modification of crushed raw materials was carried out in acid-resistant glass reactors with a capacity of $500 \mathrm{~cm}^{3}$ at the laboratory installation with water heating. In order to prevent losses the components of the solution used inverse water cooled refrigerators. On the end of processing lignocelluloses product it is was separated from the solution by filtration, washed with distilled water at $80^{\circ} \mathrm{C}$ to neutral $\mathrm{pH}$ values of wash water, then they were dehydrated and dried to moisture $5-6 \%$.

The yield of the sorbent was calculated as the ratio of the mass of the resulting product to the mass raw materials. The content of cellulose, lignin and ash in the sorption materials obtained was determined according to the methods [13].

Infrared (IR) spectra of samples were recorded on a spectrophotometer "Specord M80" (Carl Zeiss, Germany) in the range $4000-300 \mathrm{~cm}^{-1}$. The preparation of initial and modified materials to research consisted in grinding $\mathrm{KBr}$ with materials (ratio 1:100) and followed pressing in tablets.

The total volume of pores studied materials were determined by the desiccators' method by absorption of benzene vapor [16].

Sorption of testing substances: Methylene Blue and Sodium Diclofenac was performed in static conditions from solutions with concentrations of $100 \mathrm{mg} / \mathrm{l}$ and $32 \mathrm{mg} / \mathrm{l}$, respectively, at a temperature of $25^{\circ} \mathrm{C}$.

The dye solution was prepared on phosphate buffers with $\mathrm{pH}$ 6.0. Sorbent weight at the adsorption of Methylene Blue was $0.4 \mathrm{~g}$, volume of solution - $50 \mathrm{ml}$, when sorbed Sodium Diclofenac sample of sorbent - $1 \mathrm{~g}$, volume solution - $20 \mathrm{ml}$. Initial and equilibrium concentrations of the substances were determined by spectrophotometric method. The wavelength at this was $664 \mathrm{~nm}$ for Methylene Blue and $275 \mathrm{~nm}$ for Sodium Diclofenac.

The absorption efficiency of substances from aqueous solutions was determined by the formula:

$$
A_{F}=100\left(C_{o}-C_{e q}\right) / C_{0}, \%,
$$

where $\mathrm{C}_{\mathrm{o}}$ is the concentration of the substance at initial solution, $\mathrm{mg} / \mathrm{l} ; \mathrm{C}_{\mathrm{eq}}$ is the equilibrium concentration of substance, $\mathrm{mg} / \mathrm{l}$.

Study of adsorption kinetics Methylene Blue on lignocelluloses sorbents were carried out by selection through certain time intervals of bulk solution samples $4 \mathrm{ml}$, which quickly determined the concentration dye, and returned to selected solution to sorption. 


\section{Results and Discussion}

To determine the effect of conditions of modification, namely the ratio reagents in solution and duration of treatment on composition of lignocelluloses materials series of treatments with crushed shell of apricot stones were carried out by organosolvent method at $90^{\circ} \mathrm{C}$ and hydromodule 5:1.

According to the research, that increase the duration of the shell processing of stones in a media "acetic acid - hydrogen peroxide" from 30 to $150 \mathrm{~min}$ is natural leads to a decrease in the output of lignocelluloses product in all investigated range of modifying ratios reagents (Figure 1a). In all cases there is an increase in the content of cellulose in lignocelluloses materials, as evidenced data shown in Figure 1b. Results are presented in Figure 1c show that with increasing the duration of the modification the contribution of oxidative transformations increases of lignin in soluble oxidation products, i.e. there is a delignification of vegetable raw materials.

When modifying raw materials in a media "acetic acid hydrogen peroxide" in solution there are actually three types of oxidants: hydrogen peroxide, acetic acid and peracetic acid. Hydrogen peroxide in the processing process spent on the formation of peracetic acid, however, some of it is lost decomposition. Peracetic acid is essential oxidizing for lignin and transfers it to solution and thus practically does not affect plant polysaccharides of raw materials. That is why increasing the content of hydrogen peroxide in the starting solutions for delignification helps to remove more fragrances of aromatic substances (Figure 1c) and, as a result, leads to reducing the yield of the final product (Figure 1a), the cellulose content at the same time increases (Figure 1b). Such is the pattern is observed for all investigated temperature range.
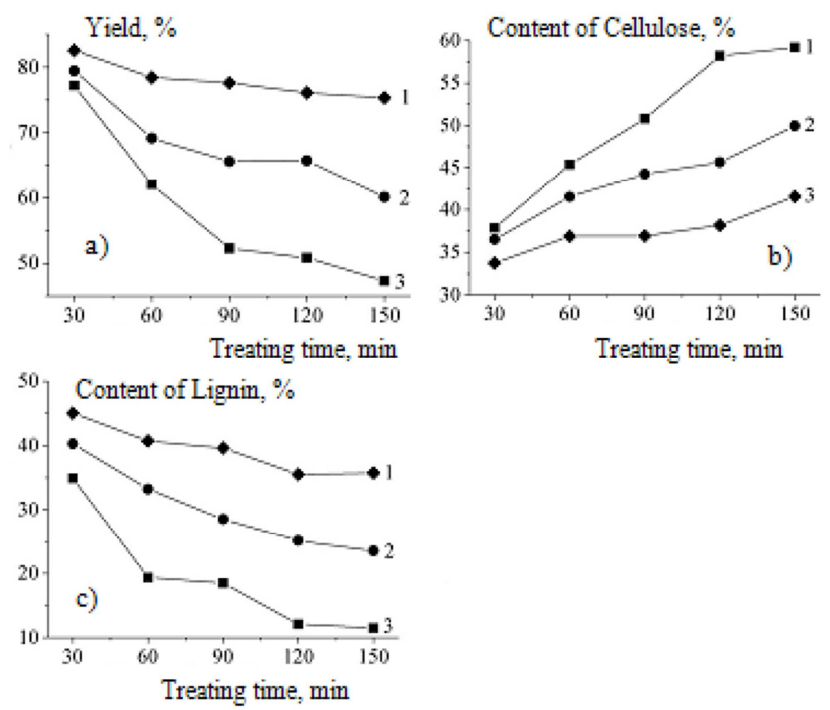

Figure 1. Dependence of the yield of products (a), their content of cellulose (b) and residual lignin (c) of the duration organosolvent treatment at different ratio of $\mathrm{CH}_{3} \mathrm{COOH}: \mathrm{H}_{2} \mathrm{O}_{2}$ in solution, vol.\%: 1 - 90:10; $2-80: 20$; $3-70: 30$.
In Figure 2 are shown the infrared spectra of the source raw materials (1) and products with different contents cellulose and lignin: 60 and $11 \%$ (2) and 38 and 39\% (3), obtained during stone modification during $120 \mathrm{~min}$ for the ratio of $\mathrm{CH}_{3} \mathrm{COOH}: \mathrm{H}_{2} \mathrm{O}_{2}$ solutions of $70: 30$ and $90: 10$ vol.\%, respectively. Wide absorption band in the $3000-3700 \mathrm{~cm}^{-1}$ for the sample of the original stones (1) indicates the presence of valence fluctuations $\mathrm{OH}$-groups (phenol and alcohol) involved in hydrogen bonds [17, 18]. Absorption band at $2900 \mathrm{~cm}^{-1}$ corresponds to symmetrical and asymmetric valence vibrations of $\mathrm{C}-\mathrm{H}$ of the methyl $\left(-\mathrm{CH}_{3}\right)$ and methylene $\left(-\mathrm{CH}_{2}-\right)$ groups. Absorption band at $1747 \mathrm{~cm}^{-1}$ in feedstock refers to valence oscillations of $\mathrm{C}=\mathrm{O}$ groups. Deformation fluctuations $\mathrm{H}-\mathrm{O}-\mathrm{H}$ of crystallization water characterizes absorption band at $1635 \mathrm{~cm}^{-1}$. To the skeletal valence vibrations $\mathrm{C}=\mathrm{C}$ of the aromatic ring structural units of lignin are attributed characteristic absorption bands at 1508,1468 and $1423 \mathrm{~cm}^{-1}$. Two absorption bands that are in the region of $1325-1378 \mathrm{~cm}^{-1}$, testify about deformation fluctuations of $\mathrm{C}-\mathrm{O}-\mathrm{H}$ bonds of phenols. Absorption band at $1243 \mathrm{~cm}^{-1}$ indicates the fluctuation of the $\mathrm{C}=\mathrm{O}$ bond in lignin structures. In the region of $1000-1155 \mathrm{~cm}^{-1}$ bands of absorption of valence are manifested oscillations of $\mathrm{C}-\mathrm{O}$ relations characteristic of primary, secondary and tertiary hydroxyl groups. In the spectrum of the source of natural material to primary hydroxyls corresponds to the absorption band at $1044 \mathrm{~cm}^{-1}$, secondary - at $1119 \mathrm{~cm}^{-1}$, tertiary - at $1154 \mathrm{~cm}^{-1}$. Absorption band at $899 \mathrm{~cm}^{-1}$ corresponds to characteristic cellulose crystallinity band. Absorption at 830 $\mathrm{cm}^{-1}$ corresponds to deformation fluctuations of $\mathrm{C}-\mathrm{H}$ bonds aromatic lignin ring.

From the shown in Figure 2 spectra show that sample (2) obtained by the oxidative-organosolvent method is larger the content of cellulose, there is a decrease relative absorption intensity in the region $1423-1508 \mathrm{~cm}^{-1}$, where the skeletal manifestations oscillations of $\mathrm{C}=\mathrm{C}$ bonds of the aromatic ring structural units. This indicates the course the process of partial delignification of the material under modification time. For sample (3) is relative the absorption intensity at the indicated the range is almost unchanged due to the high lignin content.

Research findings have also shown that despite the positive impact of the increase concentrations of hydrogen peroxide content polysaccharide component, dependence of change the content of mineral components in the final products under the same conditions are the opposite (Table 1). The minimum ash content is consistent samples obtained for the ratio $\mathrm{CH}_{3} \mathrm{COOH}: \mathrm{H}_{2} \mathrm{O}_{2}$ in $90: 10$ vol\% solutions. Removal of the mineral component is natural leads to the formation of products with more developed porous structure. Results on adsorption of benzene vapor have shown that the maximum amount of adsorption pores matches samples with minimal content mineral substances. 


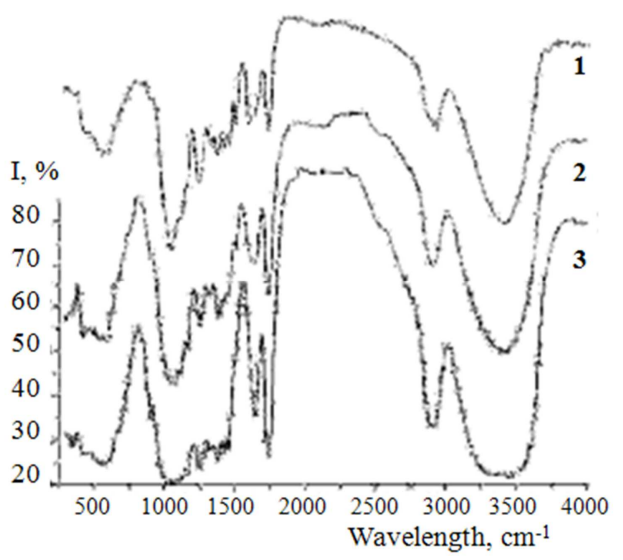

Figure 2. IR spectra of feedstock (1) and content modification products Cellulose and Lignin 60 and $11 \%$ (2) and 38 and 39\% (3).

To determine usability obtained products as biosorbents in medicine, we have also investigated sorption properties of lignocelluloses materials regarding Methylene Blue which used as mid-molecular marker for toxicants of organic nature. Except moreover, absorption capacity was determined modified natural materials for Sodium Diclofenac for the purpose of implementation preliminary evaluation of the use of lignin-celluloses materials in production drugs of prolonged action. The results obtained are also shown in the Table 1 .

Despite the larger volume adsorption pores, samples with a high content lignin are characterized by low sorption capacity against Methylene Blue. Efficiency of dye removal from aqueous solution of sorption materials from lignin and cellulose content respectively 39 and $36 \%$ is about $70 \%$.

Provided increase in cellulose content up to $60 \%$ the absorption efficiency of the dye exceeds $90 \%$. This is the pattern of sorption capacity, apparently related to the electrokinetic surface properties of natural polymer materials, namely with the ability of celluloses materials to acquire a negative charge in water media. Due to this pulp materials are characterized by high affinity for cationic dyes.

Thus, it can be argued that the fastening dyes on the surface of the material with a large high molecular weight polysaccharide content comes at the expense of not only adsorption into powder as well as the chemical interaction of the dyes cations with cellulose functional groups.

Table 1. The influence of modification conditions on the structural-sorption properties of lignocelluloses materials.

\begin{tabular}{|c|c|c|c|c|c|}
\hline \multicolumn{2}{|l|}{ Conditions of treatment } & \multirow{2}{*}{ Ash, \% } & \multirow{2}{*}{$\begin{array}{l}\text { Volume of sorption } \\
\text { pores, } \mathrm{cm}^{3} / \mathrm{g}\end{array}$} & \multicolumn{2}{|c|}{ Efficiency of adsorption, \% } \\
\hline Ratio $\mathrm{CH}_{3} \mathrm{COOH}: \mathrm{H}_{2} \mathrm{O}_{2}$, vol.\% & Duration, min & & & MB & SD \\
\hline \multirow{5}{*}{$90: 10$} & 30 & 0.19 & 0.05 & 51.5 & 0.02 \\
\hline & 60 & 0.11 & 0.06 & 63.4 & 0.71 \\
\hline & 90 & 0.09 & 0.07 & 68.4 & 1.18 \\
\hline & 120 & 0.04 & 0.07 & 70.9 & 4.65 \\
\hline & 150 & 0.04 & 0.08 & 69.7 & 4.43 \\
\hline \multirow{4}{*}{$80: 20$} & 30 & 0.31 & 0.04 & 66.3 & 0.36 \\
\hline & 90 & 0.12 & 0.06 & 79.7 & 37.4 \\
\hline & 120 & 0.11 & 0.06 & 81.0 & 43.1 \\
\hline & 150 & 0.10 & 0.07 & 82.1 & 46.9 \\
\hline \multirow{4}{*}{$70: 30$} & 30 & 0.45 & 0.04 & 68.3 & 18.9 \\
\hline & 60 & 0.33 & 0.04 & 78.5 & 54.2 \\
\hline & 90 & 0.27 & 0.05 & 90.1 & 70.1 \\
\hline & 120 & 0.22 & 0.05 & 91.0 & 81.4 \\
\hline
\end{tabular}

MB - Methylene Blue; SD - Sodium Diclofenac

Determination of kinetic characteristics sorption of the cationic dye was performed on lignocelluloses materials with content cellulose and lignin 60 and $11 \%$ and 38 and $39 \%$, in accordance. The results obtained are presented in Figure 3. The above data show that maximum absorption rate of the dye on a material with a high content of polysaccharide corresponds to the first $10 \mathrm{~min}$ of contact, within whose concentration is Methylene Blue in the solution is halved. Sorption equilibrium in these conditions as indicated material is reached within $2 \mathrm{~h}$. For specimen with a high lignin content is characteristic lower cation adsorption rate the dye is apparently limited the ability of the aromatic component to swell in aqueous solutions. However, as in the case material with a high content of cellulose, sorption equilibrium is reached during $120 \mathrm{~min}$ contact.

The results in the Table 1 are also given indicate that content can be enhanced high molecular weight polysaccharide component in the volume of lignocelluloses material as intended getting effective Sodium Diclofenac. Maximum affinity modified natural materials for anti-inflammatory drug (efficacy removal of more than $80 \%$ ) corresponds to samples from the cellulose content is about $60 \%$ the lignin content is $11 \%$. In this case, besides sorption in pores, adsorption interaction also occurs by forming hydrogen bonds between $=\mathrm{C}=\mathrm{O}$ and $=\mathrm{NH}$ with Diclofenac and hydroxyl and carbonyl groups of sorption material [19].

An increase the content of aromatic component in composition of lignocelluloses material results to significant decrease of adsorption capacity material on Diclofenac. In Figure 4 the dependency of the extraction efficiency of drug is shown for aqueous solution from lignin content in modified products. 


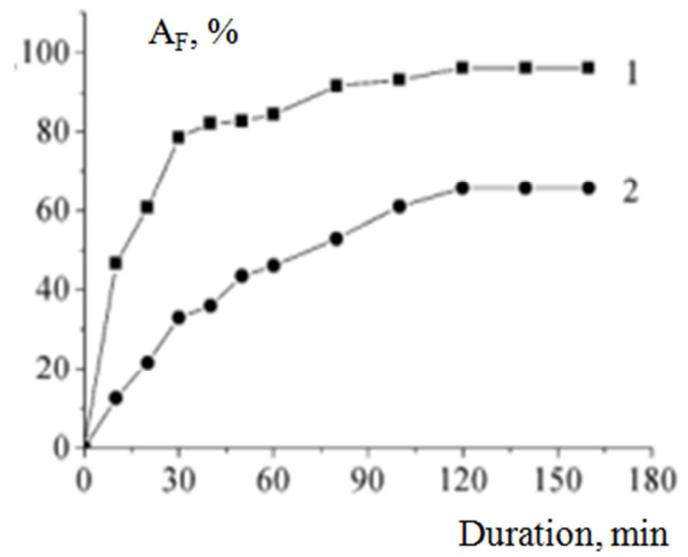

Figure 3. Dependence of absorption efficiency Methylene Blue by duration contact on samples containing Cellulose and Lignin, respectively, 60 and $11 \%$ (1) and 38 and $39 \%(2)$.

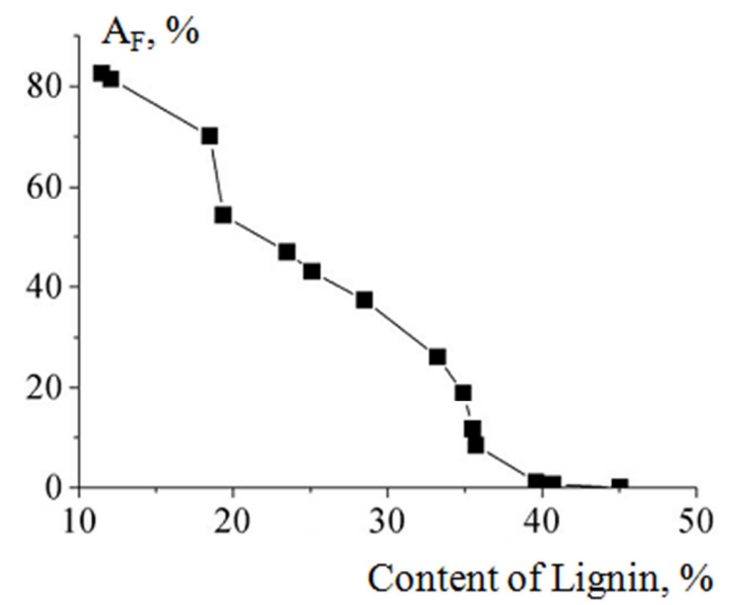

Figure 4. Dependence of absorption efficiency of Sodium Diclofenac from lignin content modified plant material.

The growth of lignin in the composition of sorbents is accompanied by an increase in the number of methoxyl groups, which leads to hydrophobization of the material. It is also sorption the ability of celluloses materials depends on packing density and decreases with increasing the degree of crystallinity. As well as show the results of IR spectroscopy (Figure 2, spectrum 3), samples containing polysaccharide and lignin 38 and $39 \%$ are characterized by greater crystallinity of cellulose, which also leads to limited swelling materials in aqueous solutions; as a result, there is no access to the functional groups.

\section{Conclusion}

The lignocelluloses materials of different chemical composition using redox method of processing plant materials in media "acetic acid - hydrogen peroxide" were obtained. Impact of modification conditions (ratio reagents, duration) on sorbent yield, content in them lignin, cellulose, and minerals, and structural sorption characteristics are investigated. It is found that the increase of hydrogen peroxide content in the reaction mixture for the oxide-organosolvent modification promotes delignification of vegetable raw materials.

The data presented is high adsorption capacity of the obtained lignocelluloses sorbents with content polysaccharide component at $60 \%$ relative marker of low molecular weight toxicants and Sodium Diclofenac.

In general, the proposed method of processing is not will only make it environmentally friendly safe way to dispose of vegetable waste food industry but will also allow with using a simple technological process of getting new products with valuable properties with possible further using modified lignocelluloses matrices in medicine for production drugs of prolonged action. Polymeric plants matrix as opposed to synthetic and inorganic, are biocompatible with body substances and "soft" by the action of the mucous membrane. Also important is that for the production of such materials China and Ukraine have sufficient raw materials, technological and technical opportunities.

\section{References}

[1] I. I. Geraschenko, Enterosorbents: Medical Drugs and Dietary Additives (scientific reference book), Kyiv: Chuiko Institute of Surface Chemistry of NAS of Ukraine, 2014, p. 248 [in Ukrainian].

[2] N. Hoenich, "Cellulose for medical applications: Past, present, and future", Bio Resources, 2006, vol. 1, N2, pp. 270-280.

[3] A. Agrawal, N. Singh, and A. Singhal, "Oxidized cellulose in prevention of Alveolar Osteitis", J. Dent. Med. Sci., 2012, vol. 22, N22, pp. 26-28.

[4] N. Shani, Z. Shani, O. Shoseyov, R. Mruwat, and D. Shoseyov, "Oxidized cellulose binding to allergens with a carbohydrate-binding module attenuates allergic reaction", J. Immunol., 2011, vol. 186, N2, pp. 1240-1247.

[5] M. A. Torlopov, "Sulphation of microcrystalline cellulose using ultrasonic activation in $\mathrm{N}$, N-dimethylformamide medium", Khimiya v interesah ustoichivogo razvitiya (Chemistry for Sustainable Development), 2011, vol. N19, pp. 555-559 [in Russian].

[6] R. D. S. Bezerra, M. M. F. Silva, A. I. S. Morais, J. A. Osajima, M. R. M. C. Santos, C. Airoldi, and E. C. S. Filho, "Phosphated cellulose as an efficient biomaterial for aqueous drug ranitidine removal", Materials, 2014, vol. 7, N12, pp. 7907-7924.

[7] Yu. A. Tarasenko, I. I. Geraschenko, and M. T. Kartel, "Enterosorption as a method of elimination of heavy metals and radionuclides from the organism", Poverkhost' (Surface), 2014, N6 (21), pp. 110-121 [in Russian].

[8] V. M. Osokin, and V. A. Somin, "Study of preparation of new adsorbents from vegetable raw materials for water purification", Polzunovskii vestnik (Polzunov' News), 2013, N1, pp. 280-282 [in Russian].

[9] E. V. Vepricova, M. L. Shipko, and E. N. Chunarev, "Properties of powder and tablet drugs based on enterosorbent from birch bast bark, Khimiya rastitel'nogo syr'ya (Chemistry of Plant Raw Materials), 2010, N2, pp. 31-36 [in Russian]. 
[10] I. V. Sheveleva, A. N. Holomeidik, and A. V. Boit, "Sorbents based on rice husk to remove (III), $\mathrm{Cu}(\mathrm{II}), \mathrm{Cd}(\mathrm{II}), \mathrm{Pb}$ (II) from solutions", Khimiya rastitel'nogo syr'ya (Chemistry of Plant Raw Materials), 2009, N4, pp. 171-176 [in Russian].

[11] A. A. Nikolaichuk, L. A. Kupchik, and M. T. Kartel, "Synthesis and properties of biosorbents derived from the lignincellulose plant raw materials - waste of agricultural complex", Sorbtsionnie i khromatograficheskie protsessy (Sorption and Chromatography Processes), 2007, vol. 7, N3, pp. 489-498 [in Russian].

[12] V. V. Galysh, M. T. Kartel, V. V. Milutin, and O. N. Bakalinskaya, "Synthesis and properties of lignocelluloseinorganic sorbents", Energotekhnologii i resursosberegenie (Energy Technologies and Resource Storage), 2014, vol. 3, pp. 28-34 [in Russian].

[13] A. V. Obolenskaya, Laboratory Works on Chemistry of Wood and Cellulose, Moscow: Ecologiya, 1991, p. 320 [in Russian].

[14] I. M. Deykun, V. V. Poyda, and V. A. Barbash, "Obtaining of cellulose from rape straw by the oxidation-organosolvent method of delignification", Naukovi visti NTUU "KPI" (Research Bulletin of NTUU “KPI”), 2010, N2, pp. 143-148 [in Ukrainian].
[15] I. M. Deykun, V. A. Barbash, and V. V. Poyda, "Obtaining of cellulose from short flax fiber by oxidative organosolvent delignification", Energotehnologii i resursosberegenie (Energy Technologies and Resource Storage), 2011, N5, pp. 22-25 [in Russian].

[16] N. V. Kel'tsev, Fundamentals of Adsorption Technology, Moscow: Khimiya, 1976, p. 511 [in Russian].

[17] F. Xu, J. Yu, T. Tesso, F. Dowell, and D. Wang, "Qualitative and quantitative analysis of lignocelluloses' biomass using infrared techniques: a mini-review", Appl. Energ., 2013, vol. 104, pp. 801-809.

[18] A. P. Karmanov, and O. Yu. Derkacheva, "The use of FTIR spectroscopy for the study of lignin's from grassy plants", Khimiya rastitel'nogo syr'ya (Chemistry of Plant Raw Materials), 2012, N1, pp. 61-70 [in Russian].

[19] R. B. Kozakevych, V. V. Yanishpolskii, and V. A. Tertykh, "Effect of porous structure of silica carriers and Diclofenac state on kinetics of active substance release, 2011, Himiya, fizika i tehnologiya poverhni (Chemistry, Physics and Technology of Surface), vol. 2, N4, pp. 470-474 [in Ukrainian]. 